\section{Epistemología de los derechos humanos como construcción social. Una propuesta desde la teoría de Berger y Luckman}

Epistemology of human rights as social construction.

A proposal from the Berger and Luckman theory

\section{Antonio Yesid Pedroza Estrada}

\section{RESUMEN}

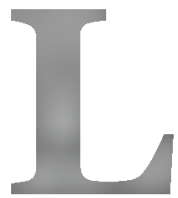

a protección de los derechos humanos, hoy, no tiene la eficacia deseada por ser tratado más como un concepto filosófico que como situación política. El problema de fondo de los derechos humanos hoy no es justificarlos sino protegerlos. Para hacerlo se requiere más trabajo del Estado, pero también, mayor comprensión y conocimiento de la sociedad para entender sus imaginarios sociales que ayuden a construir los problemas públicos y políticas públicas alrededor del tema. Esta investigación es positivista, con enfoque cualitativo, de tipo: documental, con diseño: descriptivo - deductivo, aplicando como técnica de interpretación: la hermenéutica. Las líneas teóricas principales son: Berger y Luckman, Habermas, y Bobbio. La pregunta de investigación es: ¿Se pueden fortalecer las acciones estatales en defensa y promoción de los derechos humanos a partir de comprender el imaginario social de una comunidad determinada? Las conclusiones a que se arribaran determinan que los problemas públicos consecuentes de las problemáticas sociales de derechos humanos son resultado de la construcción de imaginarios sociales consolidados mediante un lenguaje comunitario, desde donde pueden desarrollarse políticas públicas desde el Estado. Efectivizar el lenguaje de los derechos humanos no sólo es un deber, si no una estrategia que ayudaría a construir mayores escenarios de democracia, en un momento histórico que más lo necesita la humanidad.

Palabras clave: imaginarios sociales; derechos humanos; construcción colectiva.

\begin{abstract}
The protection of human rights, today, does not have the desired effectiveness because it is treated more as a philosophical concept than as a political situation.
\end{abstract}

Antonio Yesid Pedroza Estrada yesithpedroza@hotmail.com

UPC Escuela Superior de Administración Pública, ESAP

Universidad Popular del Cesar, UPC COLOMBIA

COMO CITAR ESTE ARTÍCULO Pedroza Estrada, A. Y. (2020). Epistemología de los derechos humanos como construcción social. Una propuesta desde la teoría de Berger y Luckman. Revista de la Facultad de Ciencias Económicas, 25(2), 129 - 153. http://dx.doi.org/10.30972/fce.2524569

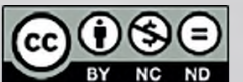

https://creativeco mmons org /licenses//by-nc-nd/4.0/ Revista de la Facultad de Ciencias Económicas ISSN $1668-6357$ (formato impreso) ISSN 1668-6365 (formato digital) por Facultad de Ciencias Económicas Universidad Nacional del Nordeste (UNNE) Argentina se distribuye bajo una Licencia Creative Commons Atribución - No Comercial - Sin Obra Derivada 4.o Internacional. 
The fundamental problem of human rights today is not to justify them but to protect them. To do so requires more work from the State, but also, greater understanding and knowledge of society to understand its social imaginaries that help to build public problems and public policies around the issue. This research is positivist, with a qualitative approach, type: documentary, design: descriptive - deductive, interpretation technique: hermeneutics. Main theoretical lines: Berger and Luckman, Habermas, and Bobbio. Research question: Can state actions in defense and promotion of human rights be strengthened by understanding the social imagination of a given community? Conclusions: The consequent public problems of the social problems of human rights are the result of the construction of consolidated social imaginaries through a community language, developing public policies from the State that make the language of human rights effective is not only a duty, but also a strategy that would help to build greater stages of democracy in a historical moment that humanity needs it most.

Keywords: social imaginaries; human rights; collective construction.

\section{INTRODUCCIÓN}

Uno de los problemas por el cual la protección de los derechos humanos en el mundo, hoy, no es tan eficaz como se quisiera, consiste en que desde el inicio de la discusión sobre hacer instrumentos de derecho internacional como acuerdos para su difusión y protección entre los países del mundo occidental, posterior a la segunda guerra mundial, este tema ha sido tratado más como un problema filosófico, idealista, en vez, de una situación práctica, donde lo que se necesita son acciones jurídico - políticas que tengan resultados efectivos.

El sofisma de la democracia como régimen político ideal, por supuesto, bajo el modelo de Europa Continental, morigerado por los ideales norteamericanos ha sido diseminado en el mundo conocido. En algunos países impuestos a la fuerza en defensa, incluso de los derechos humanos; publicitado como la única forma de gobernar en el que el soberano es "el Pueblo"; éste es el que decide sobre la forma como se construye su mundo, la manera de interpretarlo y de modificarlo. Los gobiernos establecen sus políticas públicas "escuchando a los ciudadanos" de abajo hacia arriba. La veracidad de lo anterior es una discusión infinita.

Otros pensadores opinan distinto. Muchos gobernantes e incluso intelectuales están convencidos que el poder no debe, ni puede estar en muchas manos, la mayoría "no está educada para ejercerlo". Solamente los que han sido preparados para esta tarea lo pueden hacer bien: Sofocracia. La Sofocracia es un sistema de gobierno que el filósofo griego Platón, en la Grecia antigua lo describió como el más provechoso, en un estado ideal. En la Sofocracia, no es el 
pueblo en su mayoría quien toma las decisiones, como sucede en las "democracias", donde disponen incluso los ignorantes, tampoco el que tenga más capacidad de fuerza y represión; menos los que tengan más riquezas como en la plutocracia; sino que el poder es ejercido por los sabios, por los filósofos, que son aquellos privilegiados por tener una razón tan poderosa que les permite elevarse al mundo de las ideas y encontrar lo que es verdadero y justo. El problema es que, en la actualidad, los que tienen la fuerza y la riqueza se consideran sabios.

Los gobernantes deciden cual es el modo como la ciudadanía debe interpretar el mundo, cual debe ser su cosmovisión. Finalmente, se imponen sus intereses, criterios e ideologías en unas políticas públicas diseñadas de arriba hacia abajo. No se conoce realmente que piensa, siente, sueña la gente sobre su mundo; como interpretan sus problemas sociales o cuales deben ser las soluciones a los mismos. Esto está ocurriendo con los derechos humanos, no se conoce cuales son los imaginarios sociales sobre ellos y por lo tanto no se tienen en cuenta los mismos para fortalecer el accionar del Estado y de la Sociedad Civil frente a las constantes violaciones de éstos mediante la implementación de políticas, planes, programas y proyectos eficaces.

En ese sentido, Bobbio (1992) expresó que el problema que se nos presenta, no es filosófico, sino jurídico - político. No se trata de saber cuáles y cuántos son estos derechos humanos, cuál es su naturaleza y su fundamento, si son derechos naturales o históricos, absolutos o relativos, sino cuál es el modo más seguro para garantizarlos, para impedir que, a pesar de las declaraciones solemnes, sean continuamente violados. Menos poesía y más acciones estatales.

El principal responsable de la defensa y preeminencia de los derechos humanos es el Estado; esta afirmación no tiene discusión. Pero, también es cierto que una sociedad que tiene más conocimiento sobre los mismos (su: descripción, estructura, definición, formas de reclamarlos y fortalecerlos); tendrá más oportunidad de gozarlos al poder, incluso, reclamarlos, por eso es importante conocer el significado que poseen para todos los ciudadanos, principalmente los llamados "del común", los derechos humanos.

¿Qué entiende o comprende en su cotidianeidad la comunidad sobre los derechos humanos? ¿Qué imagina que son? Más aún, ¿cómo construye imaginarios colectivos alrededor de esta temática tan importante para el desarrollo de la ciudadanía en un gobierno democrático? Es muy importante responder estas preguntas, pero el problema sobre el que se reflexiona, en este artículo, es el siguiente: ¿Se pueden fortalecer las acciones estatales en defensa y promoción de los derechos humanos, a partir de comprender el imaginario social de una comunidad determinada?

Entender lo que las personas sienten, piensan sobre un problema social o público determinado cualquiera que éste sea: derechos humanos, corrupción, paz, transparencia pública, etc., debería ser el primer paso que todo gobierno debería dar para proponer soluciones al mismo, construyendo de abajo hacia arriba, del mundo de la comunidad tal y cual es; no como propuesta o imposición de los grupos de poder, de las elites gobernantes, de arriba hacia abajo. De allí la importancia de entender los problemas públicos como: "construcciones políticas 
de una colectividad o una comunidad, en un espacio y tiempo determinado, mediante el cual logran que un problema social se incluya en la agenda de gobierno" (Pedroza, 2018, p. 125).

Los problemas públicos, que se derivan de las problemáticas sociales, son el resultado de los imaginarios sociales que se consolidan sobre intereses comunitarios, sean de construcción propia (lo ideal) o consecuencia de la multiplicidad de aparatos ideológicos actuales, que cimentan una supuesta libertad de escogencia de las personas. Precisar, entonces, el significado de los imaginarios sociales es importante en este punto.

Múltiples opiniones hay; tantas como autores, pero, la mayoría mantiene como línea estructural: "es un producto grupal, colectivo, propio de la sociedad humana". Así, para Rivas y Vázquez (2019, p. 66) "el imaginario social en las sociedades modernas es un juego de lenguaje de múltiples constelaciones arquetipales que actúan en nuestra alma, en nuestra psiquis”. Estos imaginarios están constituidos por la interactividad con los medios de comunicación, la tecnología, la movilidad, la multiculturalidad y lo pluriétnico, que construyen acuerdos, latentes o evidentes, modelan el comportamiento de los actores sociales para construir valores, actitudes, creencias, formas de ser, estar y hacer en una sociedad.

Según Cegarra (2012) "El imaginario social constituye una gramática, un esquema referencial para interpretar la realidad socialmente legitimada construido intersubjetivamente e históricamente determinado" y que por lo tanto "el imaginario debe asumirse como una matriz de significados que orienta los sentidos asignados a determinadas nociones vitales (el amor, el mal, el bien) y nociones ideológicamente compartidas (la nación, lo político, el arte, etc.) por los miembros de una sociedad" (p. 3).

Por otro lado, Botto y Méndez (2018) expresan que el término imaginario colectivo, como producto social, está directamente relacionado con la necesidad y/o capacidad que poseen grupos sociales para crear diversas realidades en determinados momentos históricos, por lo que la elaboración del imaginario es un atributo intrínsecamente social que distingue la vida en sociedad y las prácticas de las organizaciones, por lo que no se puede ignorar que los intereses de sectores del poder elaboran ideas simbólicas que hacen circular hasta convertirlas en un principio configurador del pensamiento social; de otra manera, las elites construyen muchas instituciones sociales que cimentan los imaginarios sociales.

La propuesta de este trabajo, como avance de investigación, radica en recordar la importancia que tiene comprender los derechos humanos como imaginarios sociales, construcciones colectivas, productos de una sociedad particular en un momento histórico determinado; ésta define, acuerda cuáles deben ser los derechos y obligaciones frente a los individuos, a la sociedad y al Estado, según sus valores, mitos, creencias, sueños, códigos, normas legales, etc. 


\section{METODOLOGÍA}

Esta investigación se realizó dentro del paradigma positivista, con un enfoque cualitativo. El tipo de investigación es documental, de acuerdo con Hernández, R; Fernández, C. y Baptista, P. (2016) pues tiene como propósito la revisión de fuentes documentales, recolectando, evaluando, verificando y sintetizando evidencias de lo que se investiga; con el fin de establecer conclusiones relacionadas con los objetivos de la investigación. El diseño de investigación usado es descriptivo - deductivo; respecto a lo primero, Arias (2012) lo define como la caracterización de un hecho o fenómeno intentando establecer su estructura o comportamiento. En cuanto a lo deductivo, para Sierra (2008) es un proceso que parte de un conocimiento general y arriba a uno particular, permite pasar de afirmaciones de carácter general a hechos particulares.

La técnica de interpretación utilizada es la hermenéutica, la cual es fundamental para los trabajos documentales y permite realizar la interpretación de la información obtenida. En cuanto a la técnica de recolección de datos e información fue la observación documental y el fichaje, ya que se requiere de un proceso de búsqueda y selección de temas, datos e informaciones que parten de documentos, utilizando como estrategia o plan una guía estructurada que permita en su momento la búsqueda y selección de información, para luego establecer un análisis e interpretación de ésta (Hernández, R; Fernández, C. y Baptista, P., 2016).

En cuanto a la Técnica de Análisis e interpretación de los datos, siguiendo a Hurtado (2008) se usó el análisis de contenido ya que es una técnica que permite realizar una descripción objetiva, sistemática del contenido manifiesto de comunicaciones de las cuales se pretende tener una interpretación.

\section{SOBRE LOS DERECHOS HUMANOS}

Los derechos humanos como producto cultural, social y filosófico provienen de los países occidentales, principalmente de los europeos a partir de la finalización de la segunda guerra mundial. Junto a Estados Unidos y bajo la egida de la recién creada Organización de las Naciones Unidas (ONU) expiden una serie de documentos que a pesar de solo ser declaraciones son asignadas como obligatorias, especialmente, para los países vencidos y el resto del mundo que veía con temor a los vencedores con todo su armamento nuclear incluso. Difusos al principio, pues quedaban en la zona gris muchos derechos que no eran del total agrado de las potencias militares del momento y su poderío en el resto del mundo, tal era el caso de los europeos en África y Asia. Largo fue el camino que se ha transitado hasta el día de hoy, respecto a la importancia de estos derechos humanos, su defensa y lucha para que se respeten, apliquen y extiendan a todas las poblaciones humanas del planeta. 
El proceso de sistematización sobre su contenido, clasificación, positivización, constitucionalización e internacionalización ha sido marcado por una serie de luchas sociales, donde grupos con intereses diversos han ido consiguiendo espacios de defensa de determinados derechos, logrando que se eleven a la categoría de derechos humanos. Luego, no es una discusión nueva su importancia. Lo novedoso es la propuesta de dinámicas y espacios de discusión, promoción y defensa, que proponen más acciones políticas (prácticas eficaces) y menos filosóficas. Luego, pretender entender los derechos humanos como tema de discusión de, por ejemplo, los últimos años, es por lo menos impertinente.

Sobre la efectividad en la protección internacional de los derechos humanos en los últimos años y con el objetivo de alcanzar resultados satisfactorios, fueron adoptadas iniciativas muy concretas a juicio de Vidigal (2011) como la creación de nuevos órganos, tratados, convenios o acuerdos, el funcionamiento del Alto Comisionado de Naciones Unidas para los Derechos Humanos, la instalación del Tribunal Penal Internacional, y, más recientemente, el funcionamiento del Consejo de Derechos Humanos. Sin embargo, no obstante, las relevantes conquistas en la estructura internacional, global/mundial de protección, estas no son suficientes para ultrapasar las limitaciones que impiden la efectividad del respeto de los derechos humanos, o de hacer cesar sus graves violaciones, traduciéndose, así, en un modelo de protección todavía incompleto.

Múltiples definiciones y concepciones sobre los derechos humanos vienen cargadas de humanismo e idealismo, Ledezma (2004) por ejemplo, define los derechos humanos como ciertos derechos básicos o mínimos que son inherentes a la persona y que se derivan únicamente de su condición de ser humano, esto producto, entre otras, de lo estipulado en la Carta de Los Derechos Humanos de la ONU.

La anterior afirmación merece un análisis más profundo, pues habría que preguntarse si una persona viviendo en pleno aislamiento, sin relación con otro individuo de la especie, tiene derechos humanos. Un ejemplo, en una película de Hollywood, un hombre por accidente queda solo en el planeta Marte y aprende a vivir allí, durante un largo tiempo, donde construye un entorno adecuado para él, pero donde no tiene ninguna relación con otro ser humano. ¿Podría hablarse de los derechos humanos de este individuo? ¿Pues, de tenerlos ante quien los reclamaría? ¿Como hacerlos valer? ¿Y si de repente aparecen unos "marcianos" qué derechos tendría? Los derechos humanos son esencialmente sociales, colectivos y se tienen en la medida que un conjunto de seres humanos así lo decidan.

Ledezma (2004) amplía la definición de los derechos humanos como esas prerrogativas que tiene el individuo frente al poder estatal y que limita el ejercicio del poder del Estado, buscan la salvaguarda de la persona frente al ejercicio arbitrario del poder público. Nuevamente, se habla de los derechos humanos como ideales otorgados por gracia de su naturaleza, por lo que su relación de poder frente al Estado no se discute, ya que éste (el Estado) es 
producto societal; se perciben los mismos (los derechos humanos) como una gracia proveniente, quizás, de los cielos.

El preámbulo de la Declaración Universal de los Derechos Humanos (2019), publicada por Naciones Unidas, busca el reconocimiento de la dignidad intrínseca y de los derechos iguales e inalienables de todos los miembros de la familia humana; reafirmando su fe en los derechos fundamentales del hombre, en la dignidad, el valor de la persona humana, así como la igualdad de derechos de hombres y mujeres, declarados resueltos a promover el progreso social y a elevar el nivel de vida dentro de un concepto más amplio de la libertad. Así mismo, el artículo $1^{\circ}$ expresa que "Todos los seres humanos nacen libres e iguales en dignidad $y$ derechos $y$, dotados como están de razón y conciencia, deben comportarse fraternalmente los unos con los otros".

Para ACNUR, la Oficina del Alto Comisionado de las Naciones Unidas para los refugiados (2019), los derechos humanos son aquellos que toda persona, es decir, el que pertenece al género humano y está o estuvo vivo en algún momento, sin importar su raza, sexo, etnia, lengua, nacionalidad o religión, posee como derechos inherentes desde su nacimiento. Otra vez la definición basada en el derecho natural, nacen de la nada, no hay construcción social, tampoco ningún tipo de proceso para adquirirlos.

A pesar de lo anterior, nadie discute sobre el proceso de desarrollo de éstos como resultado de luchas sociales durante siglos. El problema está en que después que se promulgaron, se aceptaron, se volvieron obligatorios en ciertos lugares y tiempos; se convirtieron en una especie de moda, donde preocupa más quien es el protagonista de la lucha del momento, o el gobernante que publica sus acciones alrededor de ellos, que lo que acontece en la realidad. $Y$ qué decir de los congresos y eventos sobre su temática, donde la mayor parte de las ponencias y disertaciones navegan por un mar de elegías, quejas y deseos sobre ellos.

Para Pedroza (2018), los derechos humanos son una construcción social - política, sobre todo de occidente, que se fue constituyendo a través de las diferentes revoluciones económicas, culturales y sociales a lo largo de la historia y que se consolidaron en la revolución francesa con la publicación de los derechos del ciudadano que más tarde, en 1948, serán la base fundamental de la creación de la llamada Declaración Universal de Derechos Humanos, promulgada por la asamblea general de la Organización de las Naciones unidas (ONU).

Henrique (2015) opina que los derechos humanos son derechos atribuidos a todos los hombres y mujeres en razón de su dignidad humana (elemento conceptual subjetivo-material) y reconocidos como universalmente válidos por un consenso global (y, complementariamente, por consensos regionales y nacionales) de los Estados y los demás sujetos internacionales (elemento histórico-procedimental).

Según Guerrero e Hinestroza (2017), los derechos reconocidos como derechos humanos son todos aquellos que los hombres legitiman como tal y cuyo desarrollo cada día es más 
extenso teniendo como finalidad, al amparo de las normas internacionales de los derechos humanos, que todas las personas se realicen humana y dignamente; en este sentido, cualquier derecho que permite este desarrollo debe calificarse como derecho humano.

De igual manera, Carpizo (2011) circunscribe los derechos humanos, primeramente, a mínimos de existencia, que el Estado debe otorgar en su orden jurídico y, subsidiariamente, a los derechos que el Estado sólo los reconoce y los garantiza en alguna medida, en la primera perspectiva se encuentran diversas concepciones o matices positivistas; en la segunda, la de derecho natural.

Bobbio (1992) recuerda que los derechos humanos, fundamentales, nacen como derechos naturales universales, se desarrollan como derechos positivos particulares, para encontrar al fin su plena realización como derechos positivos universales, sobre todo en los instrumentos internacionales elaborados a partir de la segunda guerra mundial. La realidad de la que nacen las exigencias de estos derechos fue constituida por aquellas luchas y movimientos que le habían dado vida, ser y le habían alimentado; la razón hay que buscarla en la realidad social del tiempo, en sus contradicciones en los cambios que fueron provocados por éstos.

Interesante apreciación sobre los derechos humanos realiza Arias (2015) al expresar que los derechos humanos no son ni incontrovertibles ni autoevidentes, sino que su discurso es disímbolo y contradictorio. Estos son derechos; pero que son más humanos que derechos, pues, a pesar de sostener que los derechos humanos son prerrogativas dadas a los individuos en virtud de su naturaleza humana por el hecho indubitable de ser humanos, sin importar el sexo o el género, la condición de salud o la edad, que son detentados independientemente del grupo social al que se pertenece, y que son universales en tanto que ajenos a las condiciones históricas y sociales de las culturas de pertenencia real de las personas, presenta, por decir lo menos, una serie de problemas serios y complejos; pero, sin embargo, no duda en recalcar que actualmente el concepto de derechos humanos está inserto en un ámbito teórico que difícilmente puede separarse del contexto y el campo conceptual de la cultura liberal, por lo que hoy, estos derechos, se han constituido como la única visión moderna particular del viejo compromiso con la imagen de un mundo mejor de dignidad y respeto rescatando y enarbolando la causa de la justicia.

A pesar de lo anterior, Arias (2015) insiste en afirmar que el movimiento contemporáneo de los derechos humanos, el de la más reciente esperanza utópica, no ha sido capaz de ofrecer ya no digamos solución, sino ni siquiera una plataforma teórica de comprensión ante la agudización de la serie de consecuencias perversas de la globalización frente a los mismos; la multiplicación de los riesgos en las sociedades contemporáneas y la probabilidad cada vez más alta de que la condición de víctima alcance de manera creciente a millones de personas, no parecen ser acuciantes temas para el discurso y la práctica serializada o burocratizada de los derechos humanos.

Los derechos humanos, entonces, deben efectivizarse; es decir, las acciones que se desarrollen, por el Estado o particulares, tendrán que incidir de manera directa y concreta en la 
realidad que se quiere afectar. Solo en esa medida se pueden evidenciar los cambios deseados. A manera de ejemplo, podemos hablar de algunas medidas asumidas en favor de víctimas de la violencia en Colombia contra los derechos humanos por las desapariciones forzadas de familiares resultado de procesos de sometimiento y expedición de leyes; una de las compensaciones de las que se ha hecho uso es la del "derecho a conocer la verdad", pero, la cuestión es preguntarse ¿qué tan eficaz es esa medida? ¿Qué tanto satisface a las víctimas de violación de derechos humanos conocer la verdad?

Para responder, es menester, contextualizar el derecho en cuestión. Conocer la verdad; el derecho a conocer la verdad, desde el punto de vista de Werkheiser (2020) se debe considerar como un derecho a comprender la verdad; el derecho a saber no debe ser entendido como un derecho a tener acceso a la verdad, si no, que las personas tienen derecho a comprender las injusticias, ya que el derecho a entender la verdad es una extensión natural de un derecho a la verdad simplificada, que solo puede lograrse mediante capacidades epistémicas tanto individuales como comunitarias para aquellos que poseen ese derecho.

En términos de justicia epistémica, referente a los aspectos del conocimiento, es decir, a la forma cómo éste se comunica y cómo es comprendido; no hacerlo es cometer una injusticia hermenéutica al no dar a los ciudadanos las herramientas necesarias para comprender la sociedad en la que se encuentran, que no busca soluciones a la incapacidad de entender lo que ocurre o de entender la experiencia. Si un derecho a la verdad tiene sentido, debe ser un derecho a entender esa verdad, por lo que un derecho a comprender requiere un proyecto social de desarrollo de las capacidades epistémicas de la comunidad, necesarias para desarrollar tal comprensión y lograr la justicia epistémica, que las victimas entiendan que llevó a que fuesen violentados sus derechos.

El desarrollo de estas capacidades, es pues, una obligación de los Estados y sus gobiernos, más en aquellos que han sido violadores de los derechos humanos de sus gobernados; $y$, sin lugar a dudas, un punto crítico de intervención para todo esto es, brindar una educación pública de la comunidad especialmente de los niños y jóvenes, sin sesgos ideológicos que favorezcan a un determinado aparato opresor que justifique el accionar violento de sus instituciones. Es posible que aprender de los errores del pasado nos pueda salvar en el futuro de seguir por el mismo camino defectuoso.

Finalmente, los derechos humanos, no se deben ver solamente como producto de la naturaleza del hombre, o como resultado de la inserción de algunos de ellos en normas de derecho con alcance internacional o nacional; su positivización es un logro, pero no debe perderse de vista cómo se llegó desde un extremo al otro; han sido las disputas sociales, los movimientos de algunos grupos o sectores de opinión, el influjo de élites, la dialéctica entre los derechos de las personas y el uso del Estado como instrumento de dominación por la clase hegemónica; con los primeros exigiendo y los segundos cediendo poco a poco. A futuro se espera que esta lucha siga obteniendo frutos que repercutan en una mejor calidad de vida para todos, independientemente de sus condiciones humanas. 


\section{HABERMAS Y LOS DERECHOS HUMANOS}

Otro filósofo contemporáneo importante que ha debatido el tema de los derechos humanos ha sido Habermas (2010); para la mayoría de las personas dedicadas a las ciencias sociales o humanas es, sin lugar a dudas, un referente. Habermas es sumamente crítico con respecto a la política de los derechos humanos, por eso expresa que: cuando la política de derechos humanos se convierte en una simple hoja de parra para encubrir e imponer los intereses de los más poderosos, o cuando una superpotencia desprecia abiertamente la Carta de la ONU y se arroga unilateralmente el derecho de intervención e invade un país, violando el derecho internacional humanitario, y al mismo tiempo pretende justificarse en nombre de valores universales, parecería confirmar la sospecha de que el programa de los derechos humanos consiste justamente en su abuso imperialista.

Enfatiza Habermas (2010) que los derechos humanos han sido producto de la resistencia al despotismo, la opresión y la humillación, por lo que la defensa de los éstos se nutre de la indignación de los humillados por la violación de su dignidad humana. La dignidad humana, respecto a los derechos humanos, desempeña la función de un sismógrafo que registra lo que es constitutivo de un orden democrático legal, en donde aquellos derechos que los ciudadanos de una comunidad política deben concederse a sí mismos son presididos por el respeto entre sí como miembros de una asociación voluntaria entre personas libres e iguales. Contundente es, pues, Habermas al afirmar que las declaraciones clásicas de los derechos humanos cuando se califican como innatos o inalienables, así como inherentes o naturales delatan sus orígenes religiosos y metafísicos, que desconocen la lucha social y las retrotrae a la edad media, época donde el oscurantismo golpeó duramente a la humanidad.

No obstante, a pesar de su contenido exclusivamente moral, los derechos humanos tienen la forma de derechos subjetivos exigibles, que conceden libertades y pretensiones específicas. Han sido diseñados para ser traducidos en términos concretos en la legislación democrática; para ser especificados, caso por caso, en las decisiones judiciales, y para hacerlos valer en casos de violación. De modo que los derechos humanos deben circunscribirse de manera precisa sólo en aquella parte de la moral que puede ser traducida al ámbito de la ley coercitiva y transformarse en una realidad política mediante la fórmula robusta de derechos civiles efectivos (Habermas, 2010).

Los derechos humanos pueden adquirir la calidad de derechos exigibles únicamente en el interior de una comunidad política particular, esto es, en el interior del estado-nación; pero, por otro lado, los derechos humanos están conectados con una demanda universal de validez que desborda toda frontera nacional (Habermas, 2010).

Conseguir ampliar la protección de los derechos humanos en el interior de los estadosnación, o presionar para que se difundan más allá de las fronteras nacionales, nunca ha sido 
posible sin movimientos y luchas sociales y políticas, o sin la resistencia valiente a la opresión y la degradación (Habermas, 2010).

Los derechos humanos exigen mayor efectividad, como consecuencia de las acciones de los Estados (obligación natural y positiva) y, por supuesto, de toda la comunidad, con especial énfasis en la sociedad civil. Esta insistencia que se mantiene a lo largo de este documento, es casi un imperativo, sobre todo, hoy, cuando la sociedad humana más lo necesita.

\section{LOS DERECHOS HUMANOS COMO CONSTRUCCIÓN SOCIAL DESDE EL DISCURSO EPISTÉMICO DE BOBBIO, BERGER Y LUCKMAN}

Los derechos humanos como construcción social desde el discurso epistémico de Bobbio, Berger y Luckman

El nexo entre cambio social, como generador de nuevas teorías y su repercusión en la praxis de los derechos fundamentales ha existido siempre (Bobbio, 1992). El cambio, como fenómeno humano, es una constante en la creación de los instrumentos políticos - jurídicos que vienen consolidando los derechos humanos; casi siempre, producto de confrontaciones y el Estado cediendo por las acciones de públicos con intereses particulares.

Este artículo, además, hace énfasis, principalmente, en la teoría desarrollada por Berger y Luckman (2003) sobre la construcción social de la realidad, para englobar los derechos humanos como productos de las relaciones de cambio social y lucha de poder, tal y como lo expresa Bobbio (1992).

Berger y Luckman (2003) en su libro "La construcción social de la realidad" proponen que la realidad cotidiana se encuentra dominada por la acción y la comunicación, evidenciada en el lenguaje, envuelta en un mundo ordenado mediante significados compartidos por la comunidad. La acción comunica, envía mensajes mediante códigos, pero al mismo tiempo la comunicación mueve a la acción, crea o propone nuevas realidades.

La realidad, es decir, los fenómenos que ocurren por fuera de los individuos, se construyen socialmente, al mismo tiempo que la conciencia del hombre está determinada por su ser social, por lo que afirman que "no hay pensamiento humano que esté inmune a las influencias ideologizantes de su contexto social"(Berger y Luckman (2003, p.10). El hombre es producto de la sociedad y, por lo tanto, también, todo lo que él construye, tal es el caso de los derechos humanos que provienen del constructo social, por lo que difícilmente se puede seguir sosteniendo la tesis de su origen divino.

Las formulaciones teóricas de la realidad, ya sean científicas, filosóficas, o aun mitológicas, no agotan lo que es real para los componentes de una sociedad, es decir, aquello que la gente 
conoce como realidad en su vida cotidiana, ya que existe otro conocimiento mucho mayor generado a partir de las rutinas diarias, de los hábitos, las instituciones; después de un proceso social de interacción, llamado sentido común; quizás el más importante de los sentidos pero el que menos se utiliza en el diario acontecer al momento de enfrenar las problemáticas sociales (Berger y Luckman, 2003).

Los derechos humanos son consecuencia del quehacer, pero con sentido común; un ejemplo propuesto por Bobbio (1992) expresa que la exigencia de una mayor protección a los ancianos no habría podido nacer nunca si no se hubiese producido el aumento no sólo del número de ancianos, sino también de su longevidad, consecuencias ambas de cambios acontecidos en las relaciones sociales debido a los progresos de la medicina, la alimentación, los hábitos de vida saludable.

Cierto es que la ciencia ha provisto al hombre de grandes avances que forjan una mejor calidad de vida, son claros Berger y Luckman al afirmar: "el conocimiento es un producto social y un factor de cambio social" (2003, p.111), sin embargo no se debe olvidar que "...el conocimiento teórico es sólo una parte pequeña, y en modo alguno la más importante (...). El conocimiento primario (el sentido común) con respecto al orden institucional (...) es la suma total de lo que "todos saben" sobre un mundo social, un conjunto de máximas, moralejas, granitos de sabiduría proverbial, valores y creencias, mitos, etc." (Berger y Luckman, 2003, p. 89). (El resaltado nos pertenece).

Además de percibir la realidad a través de los fenómenos externos, el hombre necesita interiorizarlos para lo que debe realizar un proceso interno llamado conocimiento. Conocer es tener la información respecto de las características de esos fenómenos ya que el cuerpo de conocimiento sobre un fenómeno determinado queda establecido socialmente como realidad (Berger y Luckman (2003).

Deviene, entonces que, en el proceso creativo, lo primero es construir el concepto de derecho y luego, el de derecho humano; pero, no sólo como algo inmanente al ser humano, si no y, sobre todo, de un complejo proceso de lucha dinámica entre intereses diversos. La libertad, la igualdad de los hombres también, no es un dato de hecho, sino un ideal a perseguir; no es una existencia, sino un valor, no un ser, sino un deber (Bobbio, 1992).

La construcción social parte de lo que acontece en la cotidianeidad de las relaciones humanas, por lo que Berger y Luckman (2003) incursionan en un nuevo método de la Sociología denominado: sociología del conocimiento, que estudia el sentido común más que las ideas, es decir, la vida cotidiana como una realidad interpretada por los hombres, que para ellos tiene el significado subjetivo de un mundo coherente. Precisamente este conocimiento del sentido común constituye el edificio de significados sin el cual ninguna sociedad podría existir. El mundo de la vida cotidiana no solo se da por establecido como realidad por los miembros or- 
dinarios de una determinada sociedad en el comportamiento subjetivamente significativo de sus vidas: "Es un mundo que se origina en sus pensamientos y acciones, y que está sustentado como real por éstos" (Berger y Luckman, 2003, p.35).

El sentido común, para Berger y Luckman (2003) se va a construir como mundo entre los sujetos cuando se clarifiquen los fundamentos del conocimiento en la vida cotidiana, o sea de las objetivaciones de los procesos y de los significados subjetivos de la realidad cotidiana establecida, encerrados en innumerables interpretaciones pre científicas y cuasi-científicas de la misma; las explicaciones se dan a partir de ideas propias, de sueños, de imaginación, incluso de ensoñación. Así, se comienzan a explicar en un tiempo - espacio determinado los derechos humanos o cualquier otro fenómeno; por ejemplo, la transparencia pública, por lo que estudiar las situaciones que se dan alrededor de este último fenómeno puede ayudar en la construcción e implementación de políticas públicas en contra de éste.

La actitud natural es la condición de la conciencia del sentido común, precisamente, porque se refiere a un mundo que es común a muchos hombres, mientras que la estructura social es la suma total de las tipificaciones y de las pautas recurrentes de interacción establecidas en la sociedad, por lo que, tanto lo uno como lo otro, se constituyen en elementos esenciales de la realidad; es decir, de la vida cotidiana, y ésta se llena, la mayoría de las veces, de interacciones reguladas por el derecho, sobre todo, en la relación Estado - comunidad, que es donde, normalmente, se estructuran los derechos humanos.

Otro concepto fundamental en Berger y Luckman (2003) para explicar la construcción de la realidad, es el lenguaje. Éste tiende puentes entre diferentes zonas de la realidad de la vida cotidiana y las integra en un todo significativo, al mismo tiempo que crea trascendencias entre los sujetos sociales. Los derechos humanos, a través de su construcción, han venido creando su propio lenguaje a nivel global, permeando la mayoría de las estructuras sociales estatales; hoy los derechos humanos hacen parte de la agenda pública internacional y nacional de cada país.

La realidad de la vida cotidiana, entendida como creación colectiva, se presenta ya objetivada; es decir, constituida por un orden de objetos que han sido designados como tales antes que la persona (naciente) aparezca en escena. Es el lenguaje quien llena la vida de objetos significativos. La persona no puede existir en la vida cotidiana sin interactuar y comunicarse continuamente con otros (significantes). Deben, pues, existir los significantes y los significados, como elementos del lenguaje, para darle sentido a la vida en sociedad. En el caso de los derechos humanos, en la medida que los significantes van creando su lenguaje, los significados, cambian o nacen, para nuevamente, transformar a los que llegan a integrar una comunidad en particular.

Las trascendencias, otro concepto importante propuesto por Berger y Luckman (2003) tienen dimensiones espaciales, temporales y sociales. Por lo que, el lenguaje permite trascender el espacio que separa las zonas manípulatorias de los individuos; como resultado de 
estas trascendencias, el lenguaje es capaz de hacer presente una diversidad de objetos que se hallan ausentes, espacial, temporal, y socialmente; en cualquier momento puede actualizarse todo un mundo a través del lenguaje. Es así como el lenguaje de los derechos humanos irrumpe en sociedades que antes no lo conocían o defendían; se presentan, principalmente, a través del lenguaje (inscrito sobre todo en las tecnologías de la comunicación) y ofrece significados que algunos significantes desconocían, así como su trascendencia, por lo que se inician los procesos de cambios sociales con todo y sus consecuencias en la sociedad y sus instituciones.

El lenguaje construye las representaciones simbólicas que parecen dominar la realidad de la vida cotidiana como gigantescas presencias de otro mundo. Crea, por supuesto (el lenguaje), un todo, que se designa como cúmulo social de conocimiento integrado; es decir, lo que todos saben, o deben saber, con su propia lógica, que permite, además, ordenar las diversas cosas que se sabe de la vida cotidiana por parte de diferentes individuos que poseen el conocimiento en grados diversos (Berger y Luckman, 2003).

La importancia del lenguaje en la construcción de los derechos humanos y de otros problemas sociales, tiene sin duda una gran función práctica, que es la de dar particular fuerza a las reivindicaciones de los movimientos que exigen para sí y para los demás la satisfacción de nuevas necesidades materiales y morales. Desarrollar políticas públicas, como herramientas exclusivas del Estado, que potencien el lenguaje de los derechos humanos, no sólo es un deber, si no una estrategia que ayudaría a construir mayores escenarios de democracia. Al Estado le conviene aumentar (desde los ámbitos de poder) los escenarios de democracia y participación que amplíen su base de legitimidad.

El lenguaje, finalmente, es lo que llena la vida de objetos significativos, como la paleta y colores del pintor. La persona existe en la vida cotidiana interactuando y comunicándose continuamente con otros seres de su especie, creando significantes y significancias. El lenguaje crea realidades sociales, al igual que las acciones; ambas se deconstruyen, construyen y reconstruyen en una relación biunívoca. Los cambios sociales son lentos, continuos, rara vez se producen saltos; las sociedades se modifican cuando sus culturas mutan; éstas son productos de nuevas costumbres que provienen de un hábito colectivizado a partir de una idea, necesidad o propuesta de un individuo en un grupo social determinado.

Los hábitos, elementos estructurales de cambios sociales, son mecanismos repetitivos que se institucionalizan. Probablemente al principio sean racionalizados; la o las personas están conscientes de lo que hacen; pero, con el tiempo son automatizados y sembrados en el inconsciente de la personas; seguramente nacen en un momento y lugar determinado a través de un individuo, pero se constituyen posteriormente, cuando la comunidad lo hace suyo colectivamente, como algo común, muchas veces con carácter obligatorio; ergo, los hábitos son elementos estructurales de la costumbre y posteriormente de la cultura. Los hábitos crean ins- 
tituciones sociales, con la historización y objetivación de las mismas; éstos, también pueden surgir de la necesidad de desarrollar mecanismos específicos de controles sociales.

Otra noción primordial en la construcción social, de Berger y Luckman (2003) es el concepto de objetividad. Éste, como cualidad de un fenómeno que el hombre enfrenta, exterior a él mismo, estructurando el mundo social. Lo decisivo de este proceso, objetivizar, conlleva a concluir que, si el mundo social fue hecho por el hombre, puede en cualquier momento rehacerlo, reconstruirlo, ya sea en forma colectiva o singular; por ejemplo, cuando un individuo ingresa a una nueva realidad social llena de significantes y significados nuevos. Insistimos, esto da a pie a que, en determinados países, hoy, se vean obligados a discutir sobre los derechos en cuestión.

Los significados humanos no se entienden como productores de un mundo si no como el resultado de las objetivaciones de la conciencia del hombre respecto de lo producido por la naturaleza. La objetivación, es decir, la significación, construye la realidad como lo sostienen Berger y Luckman (2003). Para efectos de este trabajo los significados le van a dar vida, argumentos, sustentos a las teorías de los derechos humanos.

Para intentar explicar los derechos humanos es necesario utilizar un concepto usado por Berger y Luckman (2003), la reificación. Es, sin lugar a dudas, trascendental para cimentar en la conciencia individual o colectiva categóricos significados de eventos que se dan con posterioridad a los significantes primarios y que necesitan de un nuevo proceso para reconfigurar el sentido común de las personas; a este último fenómeno se le conoce como: legitimación. Los derechos humanos se elevan a categóricos imprescindibles en la conciencia colectiva de la humanidad, reificación; pero, normalmente, terminan reconfigurándose, es decir, lo asumido como derecho en un tiempo y lugar determinado, muta, cambia, desaparece o aparece en otro, y como un hecho nuevo, moviliza intereses, públicos, que se constituyen como fuerza que reclama frente al Estado.

La legitimación, siguiendo a Berger y Luckman (2003) produce nuevos significados que sirven para integrar los ya atribuidos a procesos institucionales dispares; se presenta cuando se necesita transmitir las objetivaciones de orden institucional o históricas a una nueva generación y es evidente que las instituciones no pueden mantenerse por los recuerdos y hábitos de los individuos, así que toca restaurarlas, explicarlas y justificarlas según los elementos de la tradición institucional. Revela, además, la legitimación, un orden institucional, que atribuye validez de conocimiento a los significados objetivados y justifica el orden establecido dándole calidad de normas a las obligaciones prácticas. "La legitimación no es solo cuestión de valores, de explicar por qué se debe hacer algo; además, siempre implica también, conocimiento, por qué las cosas son lo que son" (Berger y Luckman, 2003, p. 120).

La función de la legitimación consiste en lograr que las objetivaciones de primer orden ya institucionalizadas lleguen a ser objetivamente disponibles y subjetivamente plausibles para poder cambiarlas, y que, posteriormente, se integren a una nueva realidad mediante los legitimadores, es decir, los individuos significantes del ambiente por intermedio de lo que Berger 
y Luckman (2003) denominan la alternación. Esto último, es definido como un proceso por el que atraviesa un individuo cuando entra a una nueva sociedad que contiene nuevos elementos o acuerdos diferentes a los de la cultura de donde proviene; se trata de una resocialización, que se asemeja a la socialización primaria, porque tiene que volver a atribuir acentos de su actual realidad y, consecuentemente, debe reproducir en gran medida la identificación fuertemente afectiva con los elencos socializadores que era característica de la niñez, implica, entonces, "un problema de desmantelamiento, al desintegrar la anterior estructura nómica de la realidad subjetiva y remplazarla por una nueva"(Berger y Luckman, 2003, p.195).

Comporta, por lo tanto (la alternación) una reorganización del aparato conversacional, del dialogo, del lenguaje. Los interlocutores que intervienen en el diálogo significativo van cambiando. Y el diálogo con los nuevos significantes van transformando la realidad subjetiva, que se mantiene al continuar el diálogo con ellos o dentro de la comunidad que representan. Dicho con sencillez, esto significa que hay que tener mucho cuidado de la persona con quien se dialoga. "Las personas y las ideas que discrepen con las nuevas definiciones de la realidad deben evitarse sistemáticamente”(Berger y Luckman, 2003, p. 197).

El requisito conceptual más importante para la alternación, según los autores, consiste en disponer de un aparato legitimador para toda la serie de transformaciones. Lo que debe legitimarse no solo es la realidad nueva, sino también las etapas por las que ésta se asume y se mantiene, y el abandono o repudio de todas las realidades que se den como alternativa. Pero, es importante resaltar que las objetivaciones de primer orden y las posteriores que se logren asentar a través del proceso de reificación, solo son posibles si se ha creado un mundo que interpreta la realidad de un determinado contexto, un universo simbólico colectivo propio de una comunidad.

La aparición, entonces, de este universo se produce mediante un proceso: la cristalización de los universos simbólicos que sucede después de los procesos de objetivación, sedimentación y acumulación del conocimiento; o sea que "los universos simbólicos son productos sociales que tienen una historia"(Berger y Luckman, 2003, p. 124).

El universo simbólico, es pues, considerado por Berger y Luckman (2003) como construcción cognoscitiva, es teórico. Se origina en procesos de reflexión subjetiva, los que, con la objetivación social, llevan al establecimiento de vínculos explícitos entre los temas significativos que arraigan en las diversas instituciones. "Este universo simbólico legitima el orden institucional establecido en su totalidad como conjunto significativo"(Berger y Luckman, 2003, p. 133).

Solamente después que un universo simbólico se objetiva como producto del pensamiento teórico, surge la posibilidad de reflexionar sistemáticamente sobre la naturaleza de ese universo; es en este momento que se puede dar la reificación. Al igual que lo acontecido con las instituciones cuando se quieren imponer a una nueva generación, en un momento determinado necesitan, también, ser legitimados. 
Los procedimientos para mantener los universos simbólicos son necesarios cuando ellos mismos se ha convertido en problema, igual que lo que ocurre con las instituciones, los universos simbólicos se vuelven necesario legitimarlos por medio de mecanismos conceptuales específicos; mientras esto no suceda, "el universo simbólico se auto sustenta, o sea, se auto legitima por la sola facticidad de su existencia objetiva en la sociedad de que se trate"(Berger y Luckman 2003, p. 133).

Otro importante aporte realizado por los autores estudiados viene a ser el de socialización, definido por Berger y Luckman (2003) como "la inducción amplia y coherente de un individuo en el mundo objetivo de una sociedad o en un sector de él” (p. 164); entraña parte de la explicación del tema de la investigación:

Todo individuo nace dentro de una estructura social objetiva en la cual encuentra a los otros significantes que están encargados de su socialización y que le son impuestos. Las definiciones que los otros significantes hacen de la situación del individuo le son presentadas a éste como realidad objetiva. De este modo, el individuo nace no solo dentro de una estructura social objetiva, sino también dentro de un mundo social objetivo. Los otros significantes, que mediatizan el mundo para él, lo modifican en el curso de esa mediatización (Berger y Luckman, 2003, p. 164).

Lo anteriormente expuesto, la socialización, va ser posible solamente utilizando el lenguaje, estudiado anteriormente. El lenguaje para Berger y Luckman (2003) es una fuerza generadora de realidad que posee el diálogo, objetiva el mundo y transforma las experiencias en un orden coherente. Al establecer este orden, el lenguaje realiza un mundo, en el doble sentido de aprehenderlo y producirlo.

Posteriormente, en el diálogo, las objetívizacíones del lenguaje se vuelven objetos de la conciencia individual. De esta manera, el hecho fundamental del mantenimiento de la realidad reside en el uso continuo del mismo lenguaje para objetivizar la experiencia biográfica en proceso de desenvolvimiento. En el más amplio sentido, el lenguaje común mantiene la realidad social. Cambiar el lenguaje, entonces, debe cambiar la realidad social.

Finalmente, Berger y Luckman (2003) exponen el concepto de identidad; ésta constituye, un elemento clave de la realidad subjetiva y, en cuanto tal, se halla en una relación dialéctica con la sociedad. La identidad se forma por procesos sociales. Una vez que cristaliza, es mantenida, modificada o aun reformada por las relaciones sociales. Los procesos sociales involucrados, tanto en la formación como en el mantenimiento de la identidad, se determinan por la estructura social. Recíprocamente, las identidades producidas por el inter juego del organismo, conciencia individual y estructura social, reaccionan sobre la estructura social dada, manteniéndola, modificándola o aun reformándola. "Las sociedades tienen historias en cuyo curso emergen identidades específicas, pero son historias hechas por hombres que poseen identidades específicas" (p. 214). 
Importancia notable para esta investigación trae todo el aporte de Berger y Luckman (2003) pues, "todos los universos construidos socialmente cambian porque son productos históricos de la actividad humana, el cambio es producido por las acciones concretas de los seres humanos" (p. 146); he aquí una explicación certera sobre la constitución de los derechos humanos como algo tangible por el que debe trabajarse en la búsqueda de una mejor sociedad humana.

\section{CONCLUSIÓN}

Estructurar problemas públicos como consecuencia de las problemáticas sociales relacionadas con los derechos humanos, corrupción, paz, transparencia pública, debería ser el primer paso para la construcción de políticas públicas, y estos problemas públicos se pueden concretar, de una forma, mediante el ejercicio de comunicación con la sociedad; comprender lo que las personas sienten, piensan, sueñan e imaginan en forma colectiva, partir del mundo de la comunidad tal y cual es, no como propuesta o imposición de los grupos de poder, de las elites gobernantes, de arriba hacia abajo. Los problemas públicos, que se derivan de las problemáticas sociales, son el resultado de los imaginarios sociales que se consolidan sobre intereses comunitarios.

El sentido común construye el mundo de la cotidianeidad, dando significados subjetivos a la realidad cotidiana establecida, con explicaciones que se dan con ideas propias, sueños, imaginación, incluso ensoñación, por lo que fenómenos como los derechos humanos o la transparencia pública se cimentan con el uso del lenguaje como herramienta práctica que dará fuerza a las reivindicaciones de los movimientos que exigen para sí y para los demás la satisfacción de nuevas necesidades materiales y morales.

Desarrollar políticas públicas desde el Estado, que potencien el lenguaje de los derechos humanos o de la transparencia en la administración pública, no sólo es un deber, sino una estrategia que ayudaría a construir mayores escenarios de democracia, ya que el lenguaje genera y transforma la realidad a través del diálogo, al tiempo que objetiva el mundo y transforma las experiencias en un orden coherente. Al establecer este orden, el lenguaje realiza un mundo, en el doble sentido de aprehenderlo y producirlo.

Los derechos humanos deben efectivizarse, es decir, las acciones que se desarrollen, por el Estado o por particulares deben incidir de manera directa y concreta en la realidad que se quiere afectar. Solo en esa medida se pueden evidenciar los cambios deseados. Hoy, más que buscar justificarlos debe existir un ejercicio real y eficaz de cómo protegerlos; es un problema político.

La protección y el reconocimiento de los derechos humanos que están en las constituciones democráticas modernas, deben auscultar también el imaginario social de los mismos, el individuo y la comunidad son los que tienen el derecho a decidir sobre su futuro. 
El lenguaje de los derechos humanos tiene sin duda una gran función práctica, que es la de dar particular fuerza a las reivindicaciones de los movimientos que exigen para sí y para los demás la satisfacción de nuevas necesidades materiales y morales; este lenguaje se construye, destruye y reconstruye todos los días; el Estado debe escuchar a su comunidad y establecer acciones efectivas para fomentar y proteger los derechos humanos; más acciones, menos retórica.

\section{REFERENCIAS BIBLIOGRÁFICAS}

ACNUR, Oficina del Alto Comisionado de las Naciones Unidas para los refugiados. (2019). Recuperado de:

https://eacnur.org/es/actualidad/noticias/eventos/tipos-de-derechos-humanos-segun-la-onu

Arias, F. (2012). El proyecto de investigación, introducción a la metodología científica. Editorial Episteme: Caracas, Venezuela.

Arias, J. (2015). Filosofía y política de los derechos humanos. Contribución a una teoría crítica de los derechos humanos (tesis doctoral). Universidad Nacional De Educación A Distancia. Madrid, España. Recuperado de:

http://espacio.uned.es/fez/eserv/tesisuned:DerechoJaarias/ARIAS_MARIN_Jesus_Alan_ Tesis.pdf

Berger, P., \& Luckman, T. (2003). La construcción social de la realidad. Buenos Aires: Amorrortu Editores.

Bobbio, N. (1992). El tiempo de los derechos. Madrid. Sistema. Consultado 7-11-2019. Recuperado de: http://culturadh.org/ue/wp-content/files_mf/144977835110.pdf

Botto, M., y Méndez, M. (2018). El imaginario colectivo sobre internet de los nativos digitales argentinos que ingresan a la universidad. Question, Vol. 1, N. $^{\circ} 58$, abril-junio 2018. (1-19). Universidad Nacional de La Plata: Buenos Aires, Argentina.

https://perio.unlp.edu.ar/ojs/index.php/question/article/view/4539/380o

Carpizo, J. (2011). Los derechos humanos: naturaleza, denominación y características. Revista Mexicana de Derecho Constitucional. Núm. 25, julio-diciembre 2011, pp.3-29. Universidad Au- 
tónoma de México, México D.F. Recuperado de:

http://www.scielo.org.mx/pdf/cconst/n25/n25a1.pdf

Cegarra, J. (2012). Fundamentos Teórico Epistemológicos de los Imaginarios Sociales. Cinta moebio 43: 1-13. https://scielo.conicyt.cl/pdf/cmoebio/n43/arto1.pdf

Guerrero, S. H. \& Hinestroza, L. (2017). El concepto de derechos humanos frente a los derechos de las minorías étnicas. Revista Prolegómenos Derechos y Valores, 20, 40, 27-41.

DOI: http://dx.doi. org/10.18359/prole.3039

Habermas, J. (2010). El concepto de dignidad humana y la utopía realista de los derechos humanos. Revista Diánoia, volumen LV, número 64 (mayo 2010): pp. 3-25. Recuperado de: http://www.scielo.org.mx/scielo.php?pid=s0185-24502010000100001\&script=sci_arttext; también en http://www.scielo.org.mx/pdf/dianoia/v55n64/v55n64a1.pdf

Henrique, A. (2015). La Integración de los Derechos Humanos en América Latina (tesis doctoral). Universidad de Sevilla, España. Recuperado de: http://www.corteidh.or.cr/tablas/r38065.pdf

Hernández, R; Fernández, C. y Baptista, P. (2016). Metodología de la Investigación (2da edición) México: Mc Graw Hill Interamericana Editores.

Hurtado, J. (2008). Metodología de la Investigación Holística. Servicios y Proyecciones para América Latina SYPAL. 3ra Edición. Caracas.

Ledezma, F. H. (2004). El sistema interamericano de protección de los derechos humanos aspectos institucionales y procesales. San José, Costa Rica. Instituto Interamericano de derechos Humanos. Recuperado de: https://www.iidh.ed.cr/IIDH/media/1575/si_proteccion_ddhh_3e.pdf

Naciones Unidas (ONU). (2019). Declaración Universal de los Derechos Humanos (DUDH). Recuperado de: https://www.un.org/es/documents/udhr/UDHR_booklet_SP_web.pdf

Pedroza, A. (2018). Los problemas públicos como factor estructural de las políticas públicas. Revista de la Facultad de Ciencias Económicas - UNNE. Núm. 2O, pp. 123 - 143. DOI: http://dx.doi.org/10.30972/rfce.0203258

Pedroza, A. (2018). Los desafíos sociales y el derecho como herramienta de transformación en Colombia y México. En E. Hernández y Narváez, B. (ed.), Lineamientos estructurales de una 
política pública municipal de derechos humanos. (pp. 189-209). Corporación Universitaria del Caribe y Universidad Autónoma de Tlaxcala: Anaya Editores.

Rivas, J., y Vázquez, G. (2019). El imaginario social de la calidad de vida: una revisión teónica e integradora. En Martín Castro Guzmán Josué Méndez Cano Gabriela Isabel Vázquez Díaz (Coordinadores), Participación y Calidad de Vida. Un enfoque desde Trabajo Social (pp. 66-76). https://www.acanits.org/assets/img/libros/participacion.pdf\#page=64

Sierra, R. (2008). Técnicas de investigación Social. Teoría y ejercicios. Madrid: Editorial Paraninfo.

Vidigal, A. (2011). Protección internacional de los derechos humanos - justificaciones técnicojurídicas para la creación de un tribunal mundial de derechos humanos (tesis doctoral). Universidad Carlos III De Madrid. Instituto de Derechos Humanos Bartolomé de las Casas, Madrid, España. Recuperado de: http://www.corteidh.or.cr/tablas/r30018.pdf

Werkheiser, I. (2020). A Right to Understand Injustice: Epistemology and the "Right to the Truth" in International Human Rights Discourse [Un derecho a comprender la injusticia: la epistemología y el "derecho a la Verdad"en el discurso internacional de derechos humanos]. The Southern Journal of Philosophy, 58(1), 186-199. https://onlinelibrary.wiley.com/doi/full/10.1111/sjp.12354?af=R.

\section{CURRICULUM VITAE}

\section{Antonio Yesid Pedroza Estrada}

Doctor en Ciencias Políticas. Abogado. Administrador de Empresas. Especialista en Derecho Constitucional y en Gestión Pública. Investigador categorizado por Minciencias. Docente investigador de la Escuela Superior de Administración Pública (ESAP) y de la Universidad Popular del Cesar - UPC, Colombia.

yesithpedroza@hotmail.com 